\title{
Frequency, Predisposing Factors, and Fetomaternal Outcomes of Uterine Rupture
}

\author{
Rahila Imtiaz ${ }^{1}$, Samia Husain ${ }^{2}$, Syed Hassan Ahmed Rizvi ${ }^{3}$, Syed Hussain Ahmed Rizvi ${ }^{4}$
}

\begin{abstract}
Aim: To assess the frequency of uterine rupture and its associated fetomaternal outcomes. Methods: This retrospective study was conducted at the Department of Obstetrics and Gynecology, Unit 1, Abbasi Shaheed Hospital from January 2019 to December 2019. Women with ruptured uterus diagnosed prior to or during surgery at the hospital were included. Those who had ruptured uterus secondary to congenital abnormality were excluded. Data were analyzed using SPSS version 16.0.

Results: There were 1,054 deliveries during the year 2019 and rupture was diagnosed in nine cases (0.8\%). Two women with rupture were booked and the rest were un-booked. Neglected obstructed labor was the major cause of ruptured uteri, while $44.44 \%$ cases had previous cesarean section scar. With respect to site, $66.66 \%$ of cases had ruptured anterior wall. Rupture was complete in $77.7 \%$ of cases. Hysterectomy was performed in $44.44 \%$. Two maternal and seven intrauterine deaths $(77.78 \%)$ took place in this study. Live birth rate was $22.22 \%$.

Conclusion: Our study proved that neglected prolonged labor is still claiming maternal lives in the region. Antenatal care should be made more accessible and training should be provided to traditional birth attendants to recognize and refer such cases.

Clinical significance: Traditional birth attendants need to be supervised and trained to use oxytocin. Women should be advised strictly to deliver in hospitals after a cesarean birth.

Keywords: Cesarean section, Maternal death, Perinatal outcome.

Journal of South Asian Federation of Obstetrics and Gynaecology (2021): 10.5005/jp-journals-10006-1951
\end{abstract}

\section{INTRODUCTION}

Uterine rupture is a common complication and claims many lives each year in the developing world. It happens mostly in labor but is reported to occur in antepartum period too. ${ }^{2,3}$ Multiparity, early marriages, decreased thickness of scar, and low socioeconomic status are known risk factors. ${ }^{4,5}$

Injudicious use of syntocinon is a commonly cited reason for rupture during labor. Trial of scar in women deemed unfit for trial is also a contributing factor. ${ }^{6}$ Lack of antenatal facilities and their improper utilization also plays a role when vaginal birth after cesarean section is discussed in the context of rupture. Late referrals after prolonged trial at home significantly increases chances of rupture. ${ }^{7}$

Early recognition and immediate laparotomy are life-saving in this regard. Half an hour at maximum is available before catastrophic complications set in and fetus is not salvageable after this time. ${ }^{8,9}$ Uterine rupture continues to affect mothers and their pregnancies. ${ }^{10}$ We undertook this study to assess the frequency of uterine rupture and its associated fetomaternal outcomes.

\section{Methodology}

The present study was a retrospective study. For this study we used case records of women with uterine rupture from January 2019 to December 2019. Women with ruptured uterus diagnosed prior to or during surgery at the hospital were included. Those who had ruptured uterus secondary to congenital abnormality were excluded. The cases were diagnosed on the basis of history and clinical examination and later on, confirmed on laparotomy. Formal consent was not needed, and data were coded and confidentiality ensured.

\footnotetext{
1,2Department of Gynaecology and Obstetrics, Abbasi Shaheed Hospital, Karachi, Sindh, Pakistan

${ }^{3}$ Department of Gynaecology and Obstetrics, Dow Medical College, Karachi, Sindh, Pakistan

${ }^{4}$ Department of Gynaecology and Obstetrics, Shaheed Mohtarma Benazir Bhutto Medical College, Karachi, Sindh, Pakistan

Corresponding Author: Rahila Imtiaz, Department of Gynaecology and Obstetrics, Abbasi Shaheed Hospital, Karachi, Sindh, Pakistan, e-mail: rahilaimtiaz1973@gmail.com

How to cite this article: Imtiaz R, Husain S, Rizvi SHA, et al. Frequency, Predisposing Factors, and Fetomaternal Outcomes of Uterine Rupture. J South Asian Feder Obst Gynae 2021;13(5):324-326.

Source of support: Nil

Conflict of interest: None
}

We used a pro forma to collect the data. All patients were followed up until the day of their discharge. Data were analyzed using SPSS version 16.0.

\section{Results}

During the study period, there were 1,054 deliveries during the year 2019 and rupture was diagnosed in nine cases that satisfied the inclusion criteria. The frequency of rupture was $0.8 \%$. Most women (66.67\%) were between 26 and 30 years of age and had more than two previous pregnancies (55.56\%). Of these women seven (77.78\%) were un-booked and two (22.22\%) were booked at the hospital.

Of these nine cases, four (44.44\%) had injudicious use of syntocinon at home by traditional birth attendant. The second major cause was rupture of previous caesarean scar. Lower

() The Author(s). 2021 Open Access This article is distributed under the terms of the Creative Commons Attribution 4.0 International License (https://creativecommons. org/licenses/by-nc/4.0/), which permits unrestricted use, distribution, and non-commercial reproduction in any medium, provided you give appropriate credit to the original author(s) and the source, provide a link to the Creative Commons license, and indicate if changes were made. The Creative Commons Public Domain Dedication waiver (http://creativecommons.org/publicdomain/zero/1.0/) applies to the data made available in this article, unless otherwise stated. 
uterine segment was the most common site of rupture (six cases). With respect to site, $66.66 \%$ of cases had ruptured anterior wall. In two (22.22\%) cases both anterior and posterior uterine wall were involved. Table 1 summarizes the type and site of rupture.

Bladder was involved in two (22.22\%) cases. Most women underwent major transfusion because they needed urgent resuscitation and presented to us in a state of shock.

We were able to repair the uterus without tubal ligation in three (33.33\%) women; however, repair with tubal ligation was done in two (22.22\%) women and four (44.44\%) underwent hysterectomy. Repair of bladder was undertaken in two (22.22\%) cases.

Maternal death occurred in two (22.22\%) cases. Perinatal mortality was seven (77.78\%) and live birth was two (22.22\%). Table 2 shows the fetomaternal outcomes.

Table 1: Type and site of rupture $(N=9)$

\begin{tabular}{llc}
\hline Type of rupture & $n$ & $\%$ \\
\hline Complete & 7 & 77.77 \\
Incomplete & 2 & 22.22 \\
Site of rupture & & \\
$\quad$ Anterior wall & 6 & 66.66 \\
$\quad$ Posterior wall & 3 & 33.33 \\
$\quad$ Both & 2 & 22.22 \\
Orientation of rupture & & \\
$\quad$ Longitudinal & 5 & 55.55 \\
$\quad$ Transverse & 4 & 44.44 \\
\hline
\end{tabular}

Table 2: Maternal and fetal outcomes

\begin{tabular}{lll}
\hline Maternal $(n=9)$ & $n$ & $\%$ \\
\hline Postoperative complications & & \\
$\quad$ Wound infection & 5 & 55.55 \\
Pulmonary embolism & 1 & 11.11 \\
Shock needing intensive care & 1 & 11.11 \\
Anemia & 7 & 77.77 \\
Post-op pyrexia & 7 & 77.77 \\
Maternal death & 2 & 22.22 \\
Fetal ( $n=9)$ & & \\
Intrauterine fetal deaths & 5 & 55.55 \\
Early neonatal deaths & 2 & 22.22 \\
\hline
\end{tabular}

\section{Discussion}

Rupture of the gravid uterus is an extremely unpleasant scenario which occurs due to lack of quality obstetric care. In our study the frequency of uterine rupture was 0.8 which is similar to reports from Malik, Khan et al.,11 and Ekpo. ${ }^{12}$ However, our figures are significantly higher than those reported from developed world ${ }^{13}$ which mirrors the quality of care available to our women. Women in developing countries have poor access to quality care and have higher rupture rates during labor. Our women are ill-informed about operative deliveries and have an aversion to modern obstetric practices which compels them to seek care in maternity homes, and at homes where the traditional birth attendants are not trained enough to recognize the danger signs and counsel and refer timely these women to larger centers where they could receive quality care. ${ }^{14}$
Seventy eight percent of the patients were un-booked and most of the booked patients returned to the hospital either with ruptured uterus or at a stage when it is obvious that their condition is bad. In contrast to the widespread belief that uterine rupture is a disease of multiparous women and occurs mainly in women of para 4 and above, ${ }^{15}$ in this study rupture of the uterus occurred mostly in women of low parity para $2-4$. Similar result was found in the study done by Malik where $42.71 \%$ of women were para $2-4 .{ }^{16}$ Most of these un-booked patients were brought to the hospital from remote areas of Rural Sindh. Prolonged obstructed labor was the main cause of ruptured uterus in $44.44 \%$ of cases. This observation was similar to the study done by McLaren et al. ${ }^{4}$ where $91.8 \%$ of uterine rupture cases were due to prolonged obstructed labor. But in contrast to the study done by Malik et al. rupture of previous caesarean scar was the most common cause. ${ }^{17-19}$ In our study, obstructed labor was a major cause of rupture. Previous cesarean section is an indication for a facility birth, but in our country, unattended birth at home and births by unskilled birth attendants are a norm and need to be condemned, especially for women who have a scarred uterus.

Lower uterine segment was the most common site of rupture (six cases) which is in agreement with the previous reports. ${ }^{19,20}$ In our study, complete rupture took place in $77.78 \%$ cases which was similar to the previous trend. ${ }^{20,21}$

Total abdominal hysterectomy had to be done in four cases (44.44\%) where uterus was not salvageable which was similar to the report of Ahmed and Daffalla. ${ }^{18}$ Total abdominal hysterectomy has a significant emotional impact on the woman. Most women are deeply affected by the fact that they do not have the female reproductive organ anymore which is a misconception that needs to be dispelled in these cases. These women are sometimes lost to follow up due to the sheer embarrassment and psychosocial stigma inflicted by the societal norms.

Tubal ligation has been described in cases where rupture is at multiple sites and future pregnancies may endanger the life of the woman. However, such ligation should be undertaken as an interval procedure as reversal is possible, but the chances of pregnancy after reversal are low even in expert hands.

In our study two women died (22.2\%). This was similar to some reports $^{4,10,22}$ but it was way higher than the report by Malik.Lower maternal mortality can be due to better health of the mother, because she can withstand blood loss better. However, women in our study came from rural Sindh and had bled a lot on the way and were less likely to survive. Obstructed labor is notorious for maternal morbidity in terms of pelvic floor dysfunction and urinary tract fistulae due to the pressure necrosis. Repair of bladder was undertaken in two cases. Bladder trauma is due to the position of head in the pelvic cavity at the time of cesarean. Higher incision and thinned out lower segment increases the risk of injury to the bladder. Additionally the tissue quality deteriorates due to constant pressure from the head.

In this study perinatal mortality was $77.78 \%$ which was similar to the observations of Adanu and Obed. ${ }^{23}$ The fetus is unable to survive after rupture and delivery needs to be expedited in these cases. Delays in diagnosis, reaching the hospital, and delays in the facility due to blood arrangement are major causes for this outcome. The babies do not stand a good chance if the rupture takes place at home and the woman is transported from Rural Sindh to the hospital. These women cannot be operated until and unless they are stabilized. Blood transfusion is needed and mother's life becomes priority. 
Antenatal care is still below par in the country. ${ }^{24}$ Traditional birth attendants need to be supervised and trained to use oxytocin. Women should be advised strictly to deliver in hospitals after a cesarean birth. Women should be counseled before discharge and all likely possibilities and complications of a home birth should be explained in detail so that they do not attempt home births in such cases. And lastly written and audiovisual aids should be utilized to spread awareness. Proper information regarding this serious complication should be made accessible to all women.

\section{Conclusion}

Our study proved that neglected prolonged labor is still claiming maternal lives in the region. Antenatal care should be made more accessible and training should be provided to traditional birth attendants to recognize and refer such cases.

\section{Ethical Approval}

In lieu of formal ethics committee or formal institutional review board approval, Helsinki's declaration was followed. No subjects were harmed and confidentiality was maintained.

\section{References}

1. Walsh CA, Baxi LV. Rupture of the primigravid uterus: a review of literature. Obstet Gynaecol Surv 2007;62(5):327-334. DOI: 10.1097/01. ogx.0000261643.11301.56.

2. Tesema GA, Worku MG, Teshale AB. Duration of birth interval and its predictors among reproductive-age women in Ethiopia: Gompertz gamma shared frailty modeling. PLoS One 2021;16(2):e0247091. DOI: 10.1371/journal.pone.0247091. PMID: 33606724.

3. Uzun I, Yildirim A, Kalelioglu I, et al. Spontaneous rupture of unscarred uterus at 27 weeks of gestation. Arch Gynaecol Obstet 2010;281(6);999-1001.

4. McLaren R Jr, London V, Stein JL, et al. Adverse outcomes in early term versus full-term deliveries among higher-order cesarean births. J Matern Fetal Neonatal Med 2021;1-6. DOI: 10.1080/14767058.2021.1882985.

5. Xiao J, Zhang C, Zhang Y, et al. Ultrasonic manifestations and clinical analysis of 25 uterine rupture cases. J Obstet Gynaecol Res 2021. DOI: 10.1111/jog.14666. PMID: 33470027.

6. Jongen VH, Halfwerk MG, Bauwer WK. Vaginal delivery after previous cesarean section for failure of second stage of labor. Br J Obstet Gynaecol 1998;105(10):1079-1081. DOI: 10.1111/j.14710528.1998.tb09939.x.

7. Malik HS. Frequency, predisposing factors and fetomaternal outcome in uterine rupture. J Coll Physicians Surg Pak 2006;16(7):472-475. PMID: 16827959.
8. Walsh CA, O'Sullivian RJ, Foley ME. Unexplained prelabour uterine rupture in a term primigravida. Obstet Gynaecol 2006;108 (3 Pt 2):725-727. DOI: 10.1097/01.AOG.0000195065.38149.11.

9. Bujold E, Gauthier RJ. Neonatal morbidity associated with uterine rupture: what are the risk factors? Am J Obstet Gynaecol 2002;186(2):311-314. DOI: 10.1067/mob.2002.119923.

10. Yap OW, Kim ES, Laros RK Jr. Maternal and neonatal outcome after uterine rupture in labour. Am J Obstet Gynaecol 2001;184(7): 1576-1581. DOI: 10.1067/mob.2001.114855.

11. Khan S, Parveen Z, Begum S, et al. Uterine rupture: a review of 34 cases at Ayub Teaching Hospital Abbottabad. J Ayub Med Coll Abottabad 2003;15(4):50-52. PMID: 15067834.

12. Ekpo EE. Uterine rupture as seen in the University of Calaber Teaching Hospital, Nigeria: a five-year review. J Obstet Gynaecol 2000;20(2):154-156. DOI: 10.1080/01443610062922.

13. Zwart JJ, Ricter JM, Ory F, et al. Uterine rupture in the Netherlands: a nation wide population-based cohort study. BJOG 2009;116(8): 1069-1078. DOI: 10.1111/j.1471-0528.2009.02136.x.

14. Lawson JB, Harrison KA, Berbstorm S. Obstructed labour and its consequences. In: Maternity care in developing countries. RCOG Press; 2001. p. 201-214.

15. Eze JN, Ibekwe PC. Uterine rupture at a secondary hospital in Afikpo, southeast Nigeria. Singapore Med J 2010;51(6):506-511. PMID: 20658112.

16. Gul A. Rupture of previously scarred uterus. Ann King Edward Med Coll 2004;10:473-475. Available from: https://annalskemu.org/ journal/index.php/annals/article/view/1270/981

17. Rashmi, Radhakrisknan G, Vaid NB, et al. Ruptured uterus changing Indian scenario. J Indian Med Assoc 2001;99(11):634-637. PMID: 12022205.

18. Ahmed SM, Daffalla SE. Incidence of uterine rupture in teaching hospital, Sudan. Saudi Med J 2001;22(9):757-761. PMID: 11590446.

19. Fatima N. Rupture of uterus at term. J Coll Physicians Surg Pak 1998;8(3):137-139.

20. Ofir K, Sheiner E, Levy A, et al. Uterine rupture: differences between a scarred and an unscarred uterus. Am J Obstet Gynecol 2004;191(2):425-429. DOI: 10.1016/j.ajog.2004.01.026.

21. Ezegwui HU, Nwogu-lkojo EE. Trends in uterine rupture in Enugu, Nigeria. J Obstet Gynaecol 2005;25(3):260-262. DOI: 10.1080/01443610500060768.

22. Ogunnnowo T, Oylayemi O, Aimakhu CO. Uterine rupture: $\mathrm{UCH}$, Ibadan experience. West Afr J Med 2003;22(3):236-239. DOI: 10.4314/ wajm.v22i3.27957.

23. Adanu RM, Obed SA. Ruptured uterus; a seven-year review of cases form Accra, Ghana. J Obstet Gynecol Can 2003;25(3):225-230. DOI: 10.1016/s1701-2163(16)30110-4.

24. Islam $A$, Shah AA, Jadoon $\mathrm{H}$, et al. A two-year analysis of uterine rupture in pregnancy. J Ayub Med Coll Abbottabad 2018;30 (Suppl. 1)(4):S639-S641. PMID: 30838822. 